\title{
ABORDAGENS EM SÍNTESE ASSIMÉTRICA
}

\author{
Sergio Pinheiro e Vítor F. Ferreira
}

Departamento de Química Orgânica - Instituto de Química - Universidade Federal Fluminense - Outeiro de S. João Batista s/n 24020-150 - Centro - Niterói - RJ

Recebido em 5/11/96; aceito em 7/8/97

\begin{abstract}
APPROACHES IN ASYMMETRIC SYNTHESIS. The approaches in asymmetric synthesis as the chiron approach, chiral auxiliaries, chiral reagents and asymmetric catalysis are described in a simplified way.
\end{abstract}

Keywords: asymmetric synthesis; chiron approach; chiral auxiliary; chiral reagent; chiral catalyst.

\section{INTRODUÇÃO}

Uma das fronteiras atuais da química orgânica é a síntese assimétrica ${ }^{1}$, que objetiva a preparação de substâncias enantiomericamente puras (SEP) através da síntese exclusiva ou preferencial de um estereoisômero ${ }^{2}$.

Dois enantiômeros podem apresentar ações diferenciadas sobre os organismos vivos, levando a diferentes sabores, odores, toxicidades e ações biológicas ${ }^{3}$. Tal enantiodiferenciação é baseada nas diferentes propriedades físicas dos diastereoisômeros formados a partir da interação entre os enantiômeros de um substrato e os receptores biológicos, que são macromoléculas quirais. Esta ação diferenciada dos enantiômeros de uma substância nos organismos vivos levou ao surgimento de processos industriais onde a pureza ótica é fundamental para a qualidade do produto, tais como: farmacêutica, alimentícia, de produtos agrícolas e perfumaria ${ }^{4}$.

Em muitos casos a natureza não oferece SEP em quantidades suficientes para atender a demanda industrial. Em outros, muitas SEP de interesse econômico não são naturais ${ }^{5}$. Assim, no início da década de 70, a síntese assimétrica, em substituição à resolução de racematos, ganhou destaque como método para o acesso a SEP. De fato, hoje em dia certas substâncias são preparadas industrialmente através da síntese assimétrica, tais como o aspartame e a L-DOPA ${ }^{2,6-8}$. Essa tendência deverá ser incrementada em um futuro próximo, em função da crescente intenção dos químicos orgânicos sintéticos em efetuar versões enantiosseletivas das reações orgânicas de modo a mimetizar a ação das enzimas? .

O objetivo desse trabalho é apresentar as abordagens utilizadas em síntese assimétrica, de forma a familiarizar aqueles que não estão envolvidos nessa área com o assunto e com a "linguagem assimétrica".

A síntese assimétrica possibilita a criação de novos centros quirais durante as etapas de uma síntese. Desta forma, nesse texto serão excluídas outras metodologias para a obtenção de $\mathrm{SEP}^{10,11}$ que não atendem a essa característica, tais como a resolução de racematos e o uso de blocos de construção quirais ("chiral building blocks").

As abordagens utilizadas em síntese assimétrica incluem os usos de substratos quirais ("chiron approach") ${ }^{12}$ e de substratos pró-quirais. Neste caso faz-se uso de auxiliares quirais, reagentes quirais e de catálise assimétrica ${ }^{13}$. Cabe ressaltar que, em todas essas abordagens, as substâncias quirais a serem empregadas nas sínteses (como substratos ou como auxiliares, reagentes ou catalisadores) são necessariamente produtos naturais ou seus derivados sintéticos visto que, em última análise, a natureza é a única fonte de substâncias quirais. Dentre as substâncias naturais, os carboidratos, terpenos, $\alpha$-aminoácidos e os alcalóides, além de alguns hidroxiácidos, são as principais fontes primárias usadas em síntese assimétrica ${ }^{13-15}$.

\section{O USO DE SUBSTRATOS QUIRAIS}

Esta foi a primeira metodologia empregada na literatura em síntese assimétrica sendo, por isso, um método de primeira geração. De fato, essa abordagem foi bastante popularizada por Hannesian no início da década de 80 durante a síntese total de vários produtos naturais ${ }^{12,16}$. Esta metodologia possibilita a formação de novos centros estereogênicos a partir de matériasprimas quirais através de reações diastereosseletivas, conforme o exemplo apresentado no esquema $1^{17}$.

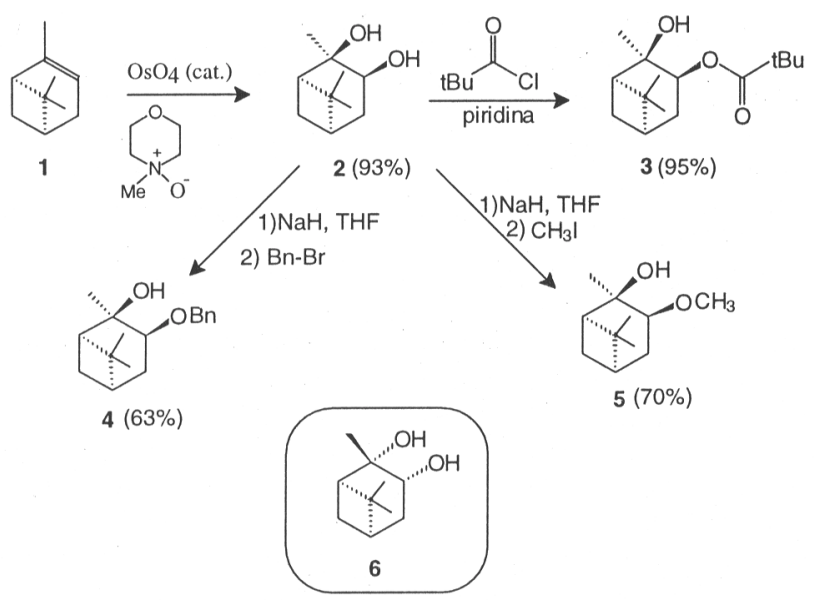

Esquema 1. O uso de substratos quirais em síntese assimétrica.

Nessa abordagem há transferência de quiralidade do substrato quiral (-)- $\alpha$-pineno (1) para o (+)-pinenodiol $(\mathbf{2})^{17}$. O curso estereoquímico da reação é dirigido pelos centros quirais já presentes no substrato quiral 1. No caso, a reação é antidiastereosseletiva visto que a hidroxilação se dá preferencialmente pela face estericamente menos impedida da olefina, que é oposta àquela da ponte presente em 1. Assim, as configurações absolutas dos novos centros quirais do intermediário quiral 2 são decorrentes da estereoquímica do substrato quiral 1 na etapa de transferência de quiralidade. Note que as etapas de transformação de $\mathbf{2}$ em $\mathbf{3 ,} \mathbf{4}$ e $\mathbf{5}$ não envolvem a formação de novos centros estereogênicos, mas apenas a reação preferencial do álcool secundário menos impedido estericamente. Assim, a 
estratégia do uso de substratos quirais é representada pela conversão de $\mathbf{1}$ em $\mathbf{2}$.

A transferência da quiralidade (transformação de 1 em 2), a princípio, poderia gerar uma mistura dos diastereoisômeros anti (2) e syn (6). A substância 2 foi obtida como um único diastereoisômero, isto é, em $100 \%$ de excesso diastereoisomérico (100\% e.d.). Isso significa que o isômero $\mathbf{6}$ não foi produzido na reação. A preferência pela formação de $\mathbf{2}$ decorre da menor energia do estado de transição que leva a 2 , em comparação àquele que conduz a 6, visto que esse é oriundo da di-hidroxilação pela face estericamente mais impedida de $\mathbf{1}$. Note que, como $\mathbf{2}$ e $\mathbf{6}$ são diastereoisômeros, os estados de transição que levam a $\mathbf{2}$ e a $\mathbf{6}$ são diastereoisoméricos e, portanto, de energias diferentes; aquele menos energético, que leva à $\mathbf{2}$, é favorecido.

$\mathrm{O}$ uso de substratos quirais é uma abordagem bastante interessante economicamente para a síntese de moléculas-alvo específicas pois a pureza ótica dos intermediários quirais (como 2) é assegurada pela quiralidade do substrato (como 1). Em que pese a sua elegância, essa abordagem pode apresentar dois problemas: primeiro, nem sempre a natureza produz substâncias quirais em elevada pureza ótica (por exemplo, o $\alpha$-pineno pode ser encontrado como racemato ou em excessos enantioméricos da ordem de $81 \%$ e.e. e de $98 \%$ e.e.). Por fim, nem sempre a transferência de quiralidade se dá com altas purezas diastereoisoméricas. De fato, em algumas reações, as transferências de quiralidade ocorrem com baixas porcentagens de excesso diastereoisomérico(\% e.d.).

Aqui cabe diferenciar as abordagens com substratos quirais e blocos de construção quirais. No primeiro, um centro quiral presente no substrato induz a formação de novos centros quirais no produto, conforme mostrado no esquema 1 para a substância 2. No segundo caso não há formação de novos centros quirais a partir deste bloco de construção quiral. Essa abordagem pode ser melhor entendida com o exemplo apresentado no esquema 2. Os centros quirais do produto 8 são aqueles já presentes no material de partida 7 (L-sorbose) e as etapas sintéticas não são conduzidas de modo a gerar um ou mais centros quirais a partir de $7^{18}$.

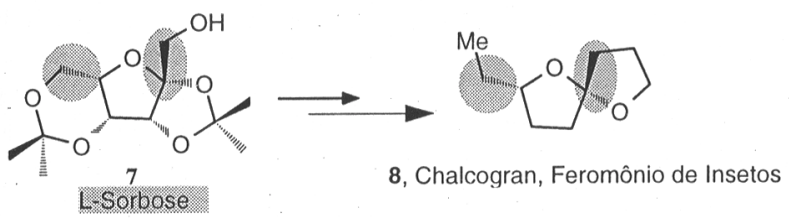

Esquema 2. Uso de blocos de construção quirais.

\section{AUXILIARES QUIRAIS}

O emprego de auxiliares quirais é um método de segunda geração em síntese assimétrica e foi desenvolvido em meados da década de 80. Essa metodologia permite a formação de centros quirais a partir de matérias-primas aquirais através de reações diastereosseletivas, conforme é mostrado no esquema $3^{19}$. $\mathrm{Na} 1^{\mathrm{a}}$ etapa, o auxiliar quiral (+)-9 reage com o cloreto de ácido gerado a partir de $\mathbf{1 0}$ levando ao éster quiral 11. Na $2^{\mathrm{a}}$ etapa, essa substância sofre uma reação diastereosseletiva (no caso, uma alquilação cinética em $\alpha$-carbonila) com transferência de quiralidade a partir de $\mathbf{1 1}$ para gerar o produto quiral $12 \mathrm{em} 62 \%$ de rendimento químico e $94 \%$ e.d. Na $3^{\text {a }}$ etapa ocorre a remoção do auxiliar para fornecer o álcool quiral $13 \mathrm{em} 86 \%$ e.e. Essa substância foi utilizada na síntese assimétrica da (R)-(+)- $\beta$-piperonil$\gamma$-butirolactona (14), um intermediário importante nas sínteses de diversas lignanas naturais biologicamente ativas ${ }^{19}$. Cabe mencionar que outros auxiliares quirais preparados a partir de carboidratos e terpenos foram empregados ${ }^{20}$ em substituição ao auxiliar (+)-9, de preço muito elevado. Porém esses novos auxiliares mostraram-se menos eficientes na produção do álcool quiral 13 em elevada pureza ótica.
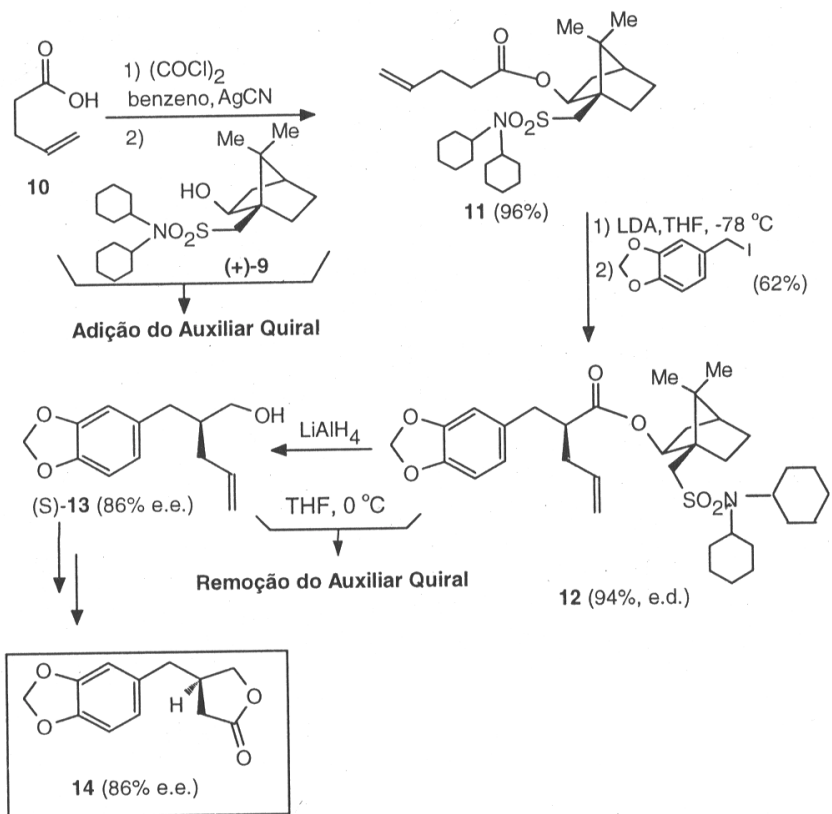

Esquema 3. Síntese assimétrica via auxiliares quirais.

Durante a remoção do auxiliar quiral (redução de 12 a 13) recupera-se o auxiliar 9, que pode posteriormente ser reutilizado. Por outro lado, essa etapa ocorre com um certo grau de racemização, o que é indesejável. Compare a menor pureza ótica de 13(86\% e.e.) em relação à $\mathbf{1 2}(94 \%$ e.d.).

$\mathrm{Na}$ etapa de transferência de quiralidade, a alquilação diastereosseletiva de $\mathbf{1 1}$ leva à formação de uma mistura dos diastereoisômeros 12 e 15 na razão diastereoisomérica de 97:3 (isto é, 12 é formado em $94 \%$ e.d.), conforme está apresentado no esquema $4^{19}$. O controle da estereoquímica levando seletivamente à $\mathbf{1 2}$ ocorre a dois níveis: primeiro, a desprotonação cinética de 11 com LDA em THF a $-78^{\circ} \mathrm{C}$ leva ao enolato $\mathbf{1 6}$ que apresenta a geometria $E$ na ligação dupla, através de um estado de transição pericíclico proposto por Ireland ${ }^{21}$. Segundo, no enolato E-16 a quelação do átomo de lítio pelo oxigênio do grupo sulfonamida produz um ciclo de 9 membros que desfavorece a rotação em torno da ligação $\mathrm{C}_{\mathrm{i}}-\mathrm{O}$ de $\mathbf{1 6}$. $\mathrm{O}$ ataque do eletrófilo ocorre preferencialmente pela face $\pi$ estericamente menos impedida $\left(\mathrm{C}_{\beta}-r e\right)$ do enolato quelado $16 \mathrm{e}$, assim, dentre os estados de transição diastereoisoméricos e competitivos que produzem 12 e $\mathbf{1 5}$ a partir de E-16, aquele que leva a 12 é menos energético.

Cabe aqui ressaltar que outros efeitos, além da quelação, como conformações preferenciais e o efeito " $\pi$-stacking",22, também podem ser responsáveis por ataques estereosseletivos sobre faces $\pi$ diastereotópicas.

Para o uso em síntese assimétrica, um bom auxiliar quiral deve apresentar certas características ${ }^{23}$ : a adição e a remoção do auxiliar ( $1^{\mathrm{a}}$ e $3^{\mathrm{a}}$ etapas no esquema 3 ) devem ser efetuadas por reações simples e em altos rendimentos químicos (e com recuperação do auxiliar quiral); a etapa de transferência de quiralidade ( $2^{\mathrm{a}}$ etapa, esquema 3 ) deve ocorrer em altas diastereosseletividades (os produtos devem apresentar altas porcentagens de excesso diastereoisomérico) e, finalmente, auxiliares quirais enantioméricos, como (+)-9 e (-)-9, devem conduzir, após a remoção do auxiliar, aos correspondentes produtos enantioméricos (S)-13 e (R)-13 em estereosseletividades semelhantes 


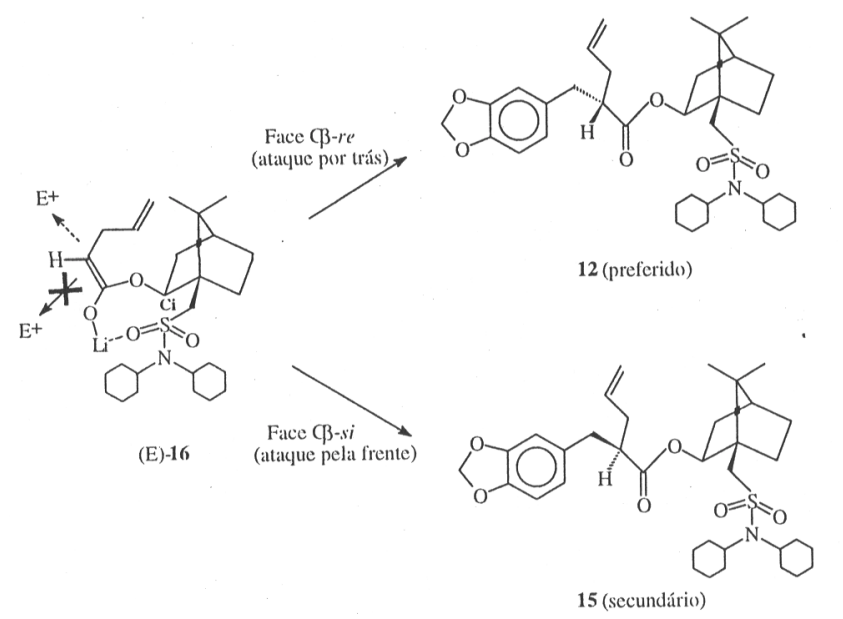

Esquema 4. Controle da seletividade pelo uso de auxiliares quirais.

(esquema 5). Evidentemente, é bastante desejável que ambos os auxiliares quirais enantioméricos (+)-9 e (-)-9 sejam preparados a partir de produtos naturais abundantes.
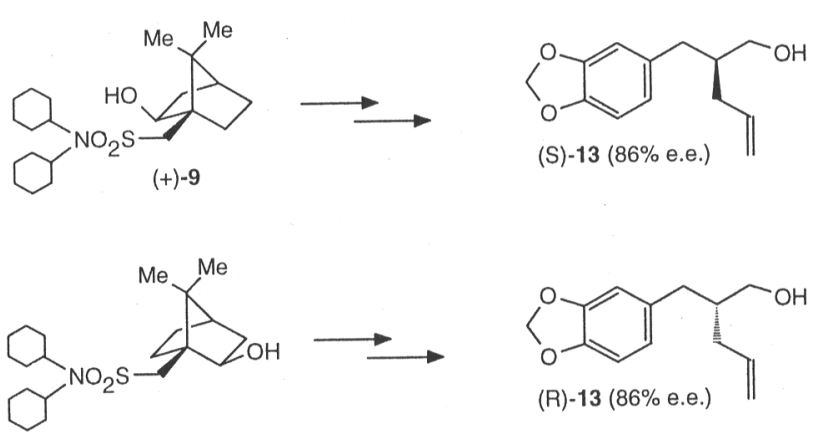

$(-)-9$

Esquema 5. Uso de auxiliares quirais enantioméricos nas síntese de (S)-13 e (R)-13.

Os auxiliares quirais podem ser assimétricos (como 9, no esquema 3) ou dissimétricos. Esses últimos, que apresentam um eixo $\mathrm{C}_{2}$ como elemento de simetria, muitas vezes levam a ótimos resultados nas etapas de transferência de quiralidade, conforme é mostrado no esquema $6^{24}$. O auxiliar 17 e a enamina 18 apresentam eixos $\mathrm{C}_{2}$ e são dissimétricos. A rotação de $180^{\circ} \mathrm{em}$ torno da ligação $\mathrm{C}-\mathrm{N}$ de $\mathbf{1 8}$ leva a $\mathbf{1 8 a}$, que é idêntico a $\mathbf{1 8}$. Tanto em 18 como em 18a, o ataque eletrofílico ocorre preferencialmente pela face $\pi$ contrária (face $\mathrm{C}_{\beta}$-si) àquela protegida pelas metilas levando, em ambos os casos, a $\mathbf{1 9}^{24}$.

O emprego de auxiliares quirais é uma abordagem mais flexível em síntese assimétrica do que o uso de substratos quirais, visto que permite uma vasta gama de desconexões retrossintéticas visando a molécula-alvo. Por outro lado, deve-se ter em mente que não existe um auxiliar quiral perfeito. Alguns deles são excelentes para certas reações, mas conduzem a baixas estereosseletividades em outras. Por exemplo, o auxiliar quiral de Oppolzer (+)-9 (esquema 3) conduz a altas seletividades nas reações de Diels-Alder ${ }^{25}$, nas adições conjugadas ${ }^{26}$, nas alquilações de enolatos ${ }^{27}$, nas oxidações e halogenações em $\alpha$ carbonila $^{28}$ e nas hidrogenações catalíticas heterogêneas ${ }^{29}$. Em contrapartida, esse auxiliar não é tão efetivo nas reduções de muitos $\beta$-cetoésteres ${ }^{30}$.

Em uma síntese assimétrica empregando auxiliares quirais, para a reação de transferência de quiralidade necessita-se de duas etapas adicionais na rota sintética: a adição e a remoção
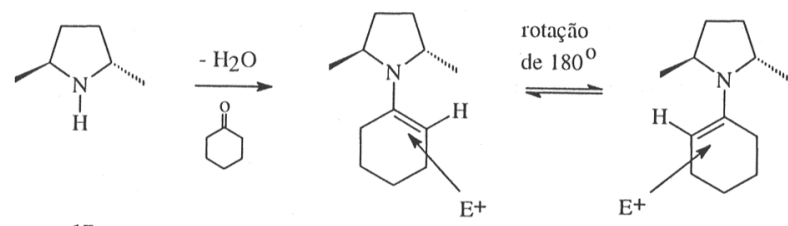

17

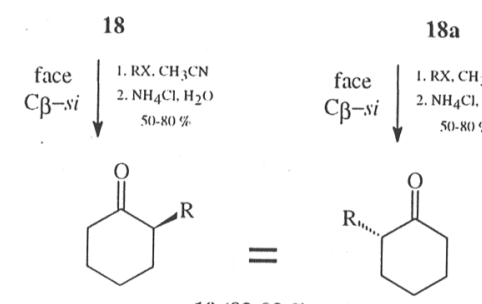

$19(82-93 \%$ e.e. $)$

Esquema 6. Auxiliares quirais dissimétricos em sintese assimétrica.

do auxiliar quiral (veja $1^{\underline{a}}$ e $3^{\underline{a}}$ etapas no esquema 3 ). A despeito disso, essa abordagem é, ainda em nossos dias, uma das mais úteis em síntese assimétrica pois, em função do grande número de modelos de estados de transição até hoje propostos para as etapas de transferências de quiralidade, pode-se compreender e prever, com certa dose de segurança, a estereoquímica absoluta dos produtos. Nesta abordagem, os esforços vêm sendo continuamente dirigidos no sentido de se produzir bons auxiliares de quiralidade que sejam menos onerosos que aqueles descritos na literatura ${ }^{4}$.

\section{REAGENTES QUIRAIS}

Embora a utilização de auxiliares quirais seja bastante empregada em síntese assimétrica, a necessidade de duas etapas adicionais (a adição e a remoção do auxiliar quiral) é uma característica pouco atraente do método. Isso pode ser evitado pelo emprego de reagentes quirais ${ }^{4}$, que é um método de terceira geração. Nessa abordagem, um substrato pró-quiral é diretamente convertido a um produto quiral pelo uso de um reagente quiral através de reações enantiosseletivas (esquema 7). O (R)-alpino-borano (20) é largamente empregado na redução de cetonas como 21a-d, em que um dos substituintes da carbonila $\left(R_{L}\right)$ seja muito mais volumoso do que o outro $\left(R_{S}\right)$. Essas reações fornecem os correspondentes álcoois $22 \mathrm{a}-\mathbf{d}$ em $44-100 \%$ de excesso enantiomérico ${ }^{31-32}$.

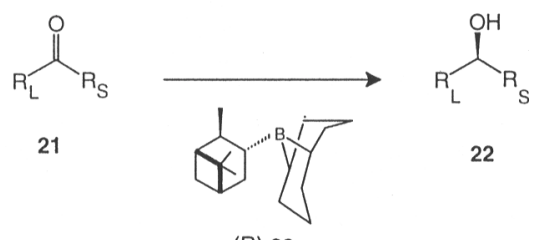

(R)-20

\begin{tabular}{cccc}
\hline $\mathbf{2 1}$ & $\mathrm{R}_{\mathrm{L}}$ & $\mathrm{R}_{\mathrm{L}}$ & \% e.e de 22 \\
\hline $\mathrm{a}$ & n-hexila & $\mathrm{CH}_{3}$ & 44 \\
$\mathrm{~b}$ & $\mathrm{Ph}$ & $\mathrm{CH}_{3}$ & 100 \\
$\mathrm{c}$ & $\mathrm{Ph}$ & $\mathrm{CH}_{2} \mathrm{Br}$ & 96 \\
$\mathrm{~d}$ & $\mathrm{RC} \equiv \mathrm{C}$ & $\mathrm{CH}_{3}$ & 100 \\
\hline
\end{tabular}

Esquema 7. Síntese assimétrica via reagentes quirais.

O controle da estereoquímica da reação ocorre a nível dos estados de transição diastereoisoméricos (e, portanto, de energias diferentes) e competitivos em bote 23 e 24 (esquema 8 ) $^{31}$. O ataque do reagente quiral (R)-20 poderia ocorrer pela face re da carbonila de $\mathbf{2 1}$ levando ao estado de transição $\mathbf{2 3}$, que gera $\mathbf{2 2}$, ou, alternativamente, pela face si de $\mathbf{2 1}$ conduzindo a $\mathbf{2 4}$. O 
estado de transição 23 é o menos energético, visto que há uma menor interação entre a metila e o substituinte menos volumoso $\left(\mathrm{R}_{\mathrm{S}}\right)$ da carbonila. Em 24, que conduz ao enantiômero ent-22, há maior interação entre a metila e o substituinte mais volumoso $\left(\mathrm{R}_{\mathrm{L}}\right)$ da carbonila.
23<smiles>CC=CC(=CC)[PH](OC(C)(C)C)(OC(C)(C)C)C1CC2CC1C2(C)C</smiles>

24<smiles>C=CC(=CC)[PH](OC(C)(C)N)(C1=C(C)C2CCC1C2(C)C)C(C)(C)C</smiles>

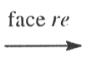

face si<smiles>[R19]C([1H])(O)[18OH]</smiles>

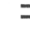

(')
Esquema 8. Controle de seletividade pelo uso da reagentes quirais.

Evidentemente, o emprego do reagente quiral (S)-20, que é enantiômero de (R)-20, leva a 22a nas mesmas seletividades mostradas no esquema 7. O método é, assim, bastante interessante visto que os reagentes quirais (R)-20 e (S)-20 são facilmente produzidos a partir do (+)- $\alpha$-pineno e do (-)- $\alpha$-pineno, respectivamente, que são abundantes na natureza ${ }^{31}$.

No contexto do emprego de reagentes quirais, cabe destacar a utilização das bases quirais, que efetuam desprotonações enantiosseletivas de hidrogênios pró-quirais na posição alfa à carbonila, permitindo posteriores substituições nessa posição, levando a produtos quirais ${ }^{33,34}$

A utilização de reagentes quirais não é uma abordagem muito desenvolvida na literatura, visto que, até o momento, o espectro de reações para os quais existem reagentes quirais efetivos é um tanto quanto limitado. Por exemplo, até hoje não há um bom reagente quiral que efetue reduções em altas porcentagens de excesso enantiomérico (\% e.e.) de cetonas 21 que apresentem pequenas diferenças de volumes entre os grupos $R_{L}$ e $R_{S}$ (vide esquema 7).

\section{CATALISADORES QUIRAIS}

O emprego de catalisadores quirais é uma abordagem de quarta geração em síntese assimétrica que vem sendo objeto de intensos esforços atualmente ${ }^{4}$. Nessa abordagem, um substrato pró-quiral é diretamente convertido a um produto quiral pelo uso de um reagente aquiral na presença de um catalisador quiral, os quais podem ser divididos em duas classes: sintéticos (por exemplo, organometálicos) ${ }^{35}$ e biológicos (microorganismos e enzimas) ${ }^{36-39}$. No exemplo selecionado ${ }^{35}$ para catalisador sintético (esquema 9), o substrato pró-quiral 25 é transformado no produto quiral $\mathbf{2 6}$ por adição de dietil-zinco (reagente aquiral) na presença do ligante quiral (-)-DAIB (27).

Em catálise assimétrica, somente uma pequena quantidade do ligante quiral $(0,05$ equivalentes em relação ao reagente aquiral) é empregada. Contudo, em certos casos, uma maior quantidade do ligante quiral é necessária, seja para se alcançar uma velocidade de conversão razoável ou para compensar perdas devidas a reações laterais. De fato, algumas vezes o ligante quiral chega a ser utilizado em quantidade estequiométrica com o reagente aquiral ${ }^{4 a, 35 b}$, conforme foi descrito por Seebach na adição de $\mathrm{EtMgBr}$ à acetofenona na presença de um equivalente de um diol como ligante quiral ${ }^{35 \mathrm{c}}$.

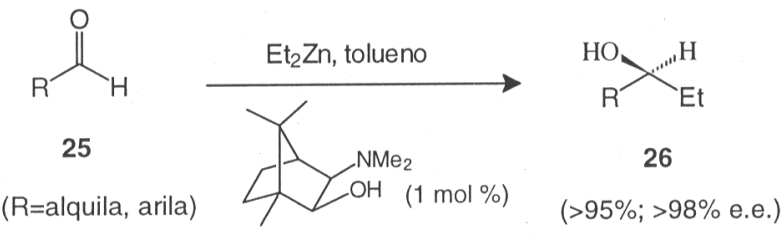

(-)-DAIB (27)

Esquema 9. Síntese assimétrica via catalisadores quirais.

Os ligantes quirais, como o (-)-DAIB, são utilizados em elevadas purezas enantioméricas. Uma nova e crescente tendência dessa abordagem consiste no emprego de ligantes quirais de baixas purezas óticas, em quantidades catalíticas, levando a produtos de altas purezas enantioméricas (porcentagem de excesso enantiomérico). Isso é denominado de amplificação cinética da quiralidade ${ }^{35 b}$. Por exemplo, o uso do (-)-DAIB (27) em $14 \%$ e.e. leva à 26 em $98 \%$ e.e. ${ }^{35}$.

No ciclo catalítico proposto por Noyori, o (-)-DAIB (27) dirige o curso estereoquímico da reação (esquema 10$)^{35}$. A reação entre o $\mathrm{Et}_{2} \mathrm{Zn}$ e o ligante quiral (-)-DAIB (27) leva à formação do catalisador quiral $\mathbf{2 8}$. O ataque de $\mathbf{2 8}$ à face re do substrato próquiral 25 gera o estado de transição 29, enquanto o ataque à face si de 25 conduz ao estado de transição 30. Novamente aqui, os estados de transição 29 e $\mathbf{3 0}$ são competitivos e diastereoisoméricos e, portanto, de energias diferentes. Nessas espécies, a rigidez do sistema é devida a uma quelação do zinco pelo oxigênio da carbonila. A maior interação entre a etila e o grupo R em $\mathbf{3 0}$ faz com que o estado de transição 29 seja preferencial e menos energético do que 30, que leva ao enantiômero 26a.

Cabe ressaltar que, nessas espécies, a quiralidade do (-)DAIB (27) é transferida ao zinco tornando-o assimétrico. O grupo etila desse complexo de zinco quiral é transferido de forma enantiosseletiva à face re de $\mathbf{2 5}$.
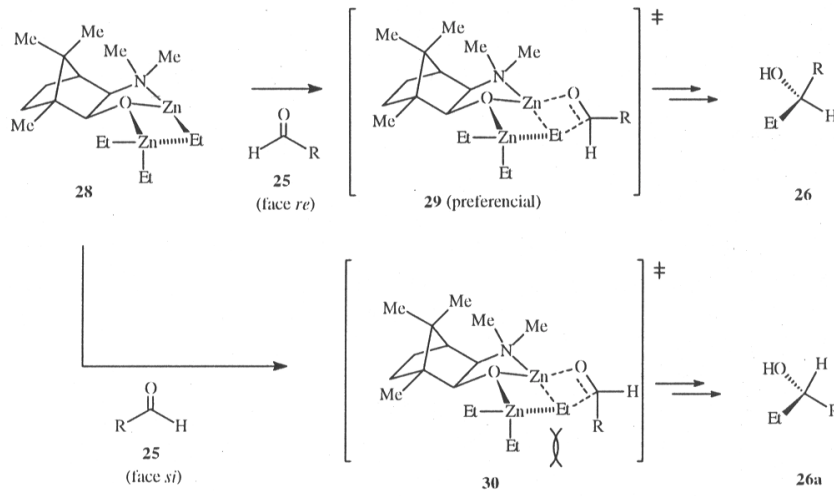

26

Esquema 10. Controle da seletividade pelo uso de catalisador quiral.

Além de dirigir o curso estereoquímico da reação, o (-)DAIB (27) acelera a reação por complexação com o dietilzinco. De fato, para que um ligante quiral (como o (-)-DAIB) possa ser empregado em quantidades catalíticas, é necessário que a reação entre o substrato pró-quiral (no caso, 25) e o reagente aquiral (dietilzinco) seja bastante lenta, de modo a permitir que o reagente aquiral dietil-zinco se complexe com o ligante quiral (-)-DAIB antes de atacar o substrato pró-quiral 25. Por exemplo, uma vez que os reagentes de Grignard (EtMgBr) e os compostos organolítio (EtLi) adicionam-se rapidamente à carbonila, um ligante quiral não poderia ser usado em escala catalítica, pois o excesso desses organometálicos reagiria com a carbonila pró-quiral 25 levando ao álcool 26 como uma mistura racêmica. Isso, evidentemente, causaria uma diminuição da \% e.e. de $\mathbf{2 6}$ ao se usar o ligante quiral em escala catalítica. 
Também é bastante descrito na literatura o uso de ligantes quirais dissimétricos (eixo $\mathrm{C}_{2}$ ) em diversas reações sob catálise quiral. Por exemplo, a adição de organozinco a aldeídos próquirais é feita em altas purezas óticas ( $>90 \%$ e.e.) na presença de um ligante quiral derivado do ácido tartárico complexado com $\mathrm{Ti}\left(\mathrm{OPr}^{\mathrm{i}}\right)_{4}{ }^{40}$.

No contexto da biocatálise, cabe ressaltar que as reações enzimáticas promovem uma série de reações em substratos próquirais, tais como: reduções de carbonilas (na presença dos cofatores NADH ou NADPH, que são os agentes redutores $)^{41}$, oxidações de álcoois e de anéis aromáticos ${ }^{42}$ e hidrólise de ésteres ${ }^{43,44}$.

Algumas dificuldades maiores se impõem quanto ao uso de catalisadores quirais em síntese assimétrica: uma é devida ao número até hoje restrito de reações estudadas ${ }^{35 b}$. Outra diz respeito aos custos dos ligantes quirais, especialmente quando esses são empregados em quantidades estequiométricas. De fato, muitas dessas substâncias ou não são comerciais ou são de custos muito elevados. Outra dificuldade é que, na maioria das reações até hoje estudadas, não se conhecem os ciclos catalíticos. Isto dificulta enormemente a compreensão do curso estereoquímico da reação, bem como a previsão das configurações absolutas dos produtos. Em contrapartida, a possibilidade de uso de ligantes quirais em quantidades catalíticas é bastante atraente para os processos industriais em larga escala, onde o fator custo é crítico. Por exemplo, a L-DOPA e o (S)-naproxen são fármacos produzidos industrialmente através da hidrogenação homogênea com catalisadores de $\mathrm{Rh}$ ou de Ru utilizando as difosfinas (R,R)-DIPAMP e (S)-BINAP, respectivamente, como ligantes quirais dissimétricos. ${ }^{45}$

\section{DUPLA INDUÇÃO ASSIMÉTRICA}

Esta abordagem foi inicialmente descrita por Masamune e combina os métodos de primeira a quarta gerações (substrato quiral, auxiliares quirais, reagentes quirais e catalisadores quirais $)^{46}$. No exemplo mostrado no esquema 11 , a reação aldólica entre o aldeído quiral 31 e os boroenolatos 32a-c leva à uma mistura dos $\beta$-hidroxicarbonilados 33 e 34. A quiralidade de $\mathbf{3 1}$ tem um pequeno efeito no controle das estereoquímicas de 33 e 34, pois o uso de 32a $(R=S P h)$ leva predominantemente a $\mathbf{3 3}$ na razão de 3:2. Nesse caso, a estereosseletividade é controlada pela regra de $\mathrm{Cram}^{46}$. Nas induções assimétricas múltiplas, o uso de reagentes enantioméricos como 32b e 32c leva a produtos de configurações opostas, mas em diastereosseletividades diferentes. Isso é explicado pelo conceito de pares de reagentes "matched" e "mismatched" 46 .

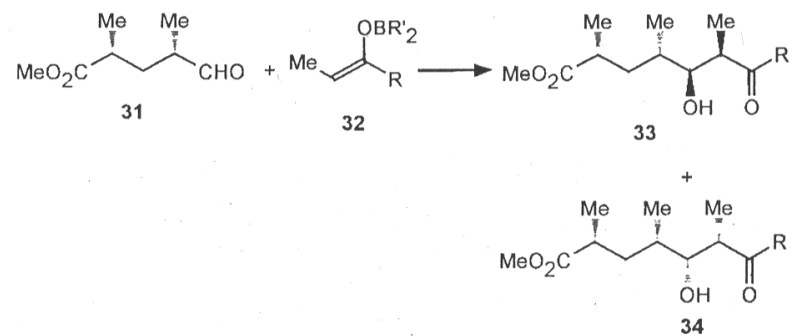

\begin{tabular}{ccc}
\hline Entrada & 32 & $\mathbf{3 3 - 3 4}$ \\
\hline $\mathrm{a}$ & $\mathrm{R}=\mathrm{SPh}$ & $3: 2$ \\
$\mathrm{c}$ & $>100: 1$ \\
$\mathrm{c}$ & & \\
\hline
\end{tabular}

Esquema 11. Dupla indução assimétrica.
A alta estereosseletividade na formação de $\mathbf{3 3}$ mostra que as estereoquímicas de $\mathbf{3 1}$ e de $\mathbf{3 2 b}$ induzem o curso estereoquímico da reação no mesmo sentido. Logo, 31 e 32b são pares de reagentes "matched". A menor seletividade na formação de $\mathbf{3 4}$ indica que as estereoquímicas de $\mathbf{3 1}$ e de $32 \mathrm{c}$ induzem o curso estereoquímico da reação em sentidos contrários e, assim, 31 e 32c são pares de reagentes "mismatched" 46.

As triplas induções assimétricas começaram a ser descritas mais recentemente ${ }^{4 a}$. Neste caso, o aldeído quiral $\mathbf{3 1}$ reage com um boroenolato 32 que apresenta quiralidade não só na porção $\mathrm{R}$, mas também nos grupos $\mathrm{R}$ ' ligados ao boro.

\section{A QUESTÃO ATUAL DO MERCADO FARMACÊUTICO}

Com o desenvolvimento da química farmacêutica, propiciado pelos avanços da química orgânica sintética e da farmacologia, a estrutura básica dos produtos ativos foi sendo modificada no sentido de se descobrir moléculas mais simples que contivessem a porção estrutural responsável pela atividade biológica presente na molécula natural. Rapidamente foram sendo acumulados uma grande quantidade de resultados envolvendo as relações entre a estrutura molecular e as propriedades biológicas, possibilitando o planejamento e o desenvolvimento de novas substâncias bioativas. Como resultado desta tendência, substâncias de natureza sintética, facilmente preparadas em laboratório, passam a predominar no arsenal terapêutico em substituição aos produtos naturais, por vezes isolados em pequenas quantidades, constituindose hoje em dia em $75 \%$ do seu total ${ }^{10,11}$.

Exceção feita aos fármacos semi-sintéticos, produzidos a partir de matérias-primas naturais (antibióticos, hormônios esteroidais, glicosídeos cardíacos), os demais foram produzidos, estudados e licenciados para a venda em suas formas racêmicas ${ }^{47}$. Atualmente, dentre os fármacos existentes, $72 \%$ são derivados de substâncias sintéticas e o restante de origem natural ou semissintéticos. Apenas $40 \%$ dos fármacos sintéticos contêm um centro quiral. Porém, dentre os fármacos derivados de substâncias naturais ou semissintéticas, $99 \%$ deles são quirais.

Durante décadas a questão da quiralidade e, conseqüentemente, da pureza ótica foi um fator negligenciado pela comunidade científica (caso da talidomida) ${ }^{48}$ e pela indústria farmacêutica. Ao passo que os produtos naturais usados em terapêutica são oticamente puros, os de estrutura quiral de origem sintética eram utilizados na forma de misturas racêmicas, visto que os métodos de síntese assimétrica disponíveis até então não eram eficientes e os custos para a resolução dos racematos eram altos e oneravam substancialmente a produção industrial.

Atualmente a "Food and Drug Administration"-USA (FDA) e outro órgãos semelhantes da comunidade Européia e do Japão têm novos protocolos que devem ser seguidos para a liberação de uma nova droga, em especial se a sua estrutura for quiral $^{49-52}$. O uso de uma mistura racêmica para novos medicamentos só é permitido se todos os ensaios clínicos e toxicológicos forem realizados com cada enantiômero isoladamente e comparados com aqueles envolvendo a mistura racêmica $^{53}$. O efeito destes novos protocolos foi imediatamente refletido no tempo e no custo para a liberação de uma nova droga quiral e nas buscas por abordagens sintéticas mais eficientes e abrangentes. Neste aspecto, a síntese assimétrica se tornou a fronteira mais proeminente da química orgânica nos dias atuais, principalmente na busca de matérias primas quirais mais acessíveis ${ }^{54-57}$.

\section{CONCLUSÕES}

A síntese de substâncias enantiomericamente puras continua atraindo a atenção da comunidade científica. A catálise assimétrica e as transformações enzimáticas ocupam atualmente as fronteiras na busca de novos procedimentos em síntese assimétrica. 
O emprego de catalisadores, de reagentes e de auxiliares quirais em síntese assimétrica são abordagens mais abrangentes do que o uso de substratos quirais e transformações enzimáticas, pois permitem um maior espectro de desconexões retrossintéticas visando a molécula-alvo. De qualquer forma, em todas essas abordagens, o princípio do controle da estereosseletividade é o mesmo: nas reações a partir de substâncias quirais, há formação de estados de transição diastereoisoméricos e competitivos. A estereoquímica do produto principal é decorrente da reação preferencial que ocorre através do estado de transição menos energético.

Nas abordagens a partir de substratos quirais e do uso de reagentes e de auxiliares quirais, uma substância enantiomericamente pura (SEP) é empregada em quantidades estequiométricas com a substância de partida, sendo que, em alguns casos, a SEP pode ser recuperada e reutilizada. Em contraste, no emprego de catalisadores quirais, em muitos casos a SEP é utilizada em quantidades catalíticas, o que faz dessa abordagem um refinamento final em termos de síntese assimétrica.

Finalmente, há que se ressaltar que um enorme progresso foi alcançado na síntese industrial de substâncias enantiomericamente puras, pois o químico orgânico sintético dispõe atualmente de um arsenal considerável de metodologias em síntese assimétrica. Portanto, o argumento de que não existe tecnologia disponível para preparação de drogas oticamente puras, já não justifica que essas sejam comercializadas sob as formas de racematos.

\section{REFERÊNCIAS}

1. a) Seebach, D.; Angew. Chem. Int. Ed. Engl. 1990, 29, 1320; b) Whitesides, G.; Angew. Chem. Int. Ed. Engl. 1990, 29, 1209; c) Sheldon, R. A.; Chirotechnology: Industrial Synthesis of Optically Active Compounds; Marcel Dekker, N.Y. 1993; d) Hudlick, T.; Chem. Rev. 1996, 96, 3.

2. a) Trost, B. M.; Stereocontrolled Organic Synthesis: A Chemistry for the 21st Century; Blacwell, Oxford 1994; b) Davies, S. G.; Brown, J. M.; Pratt, A. J.; Fleet, G.; Chemistry in Britain 1989, 259; c) Noyori, R.; Chemtech. 1992, 360; d) Berrisford, D. J.; Bolm, C.; Sharpless, K.; Angew. Chem. Int. Ed. Engl. 1995, 34, 1059.

3. a) Thall, E.; J. Chem. Ed. 1996, 481; b) Stinson, S. C.; Chem. \& Eng. News 1994, September 19, 38.

4. a) Aitken, R. A.; Gopal, J.; Asymmetric Synthesis; Aitken, R. A.; Kilényi, S. N.; Editors, Blackie Academic \& Professional, London 1994, cap.4; 4b) Pinheiro, S.; Saraiva, A. S.; Campos, M. P. A.; J. Braz. Chem. Soc. 1966, 7, 353.

5. a) Wainer, I. W.; Drug Stereochemistry: Analytical Methods and Pharmacology; Marcel Dekker Inc.; NY; 1993; b) Cowin, H.; Peter, G.; Taylor, J. B.; Comprehensive Medicinal Chemistry. The Rational Design, Mechanistic \& Terapeutic Application of Chemical Compounds; Pergamon Press, Oxford 1990.

6. Scott, J. W.; Top. Stereochem. 1989, 19, 209.

7. Kotha, S.; Tetrahedron 1994, 50, 3639.

8. Sheldon, R. A.; Drug Inf. J. 1990, 24, 129.

9. a) Boyd, M.R.; Current Therapy in Oncology; B. C. Decker Inc.; NY, 1992, 11; b) Wong, C. H.; Whiteside, G. M.; Enzymes in Synthetic Organic Chemistry; Elsevier, Oxford 1994; c) Wong, C.-H.; Pure \& Appl. Chem. 1995, 67, 1609.

10. Deutsch, D. H.; Chemtech 1991, 157.

11. Stinson, S. C.; Chem. \& Eng. News 1992, 46.

12. a) Hannesian, S.; Total Synthesis of Natural Products: The Chiron Approach; Pergamon, Oxford 1983; b) Blaser, H. V.; Chem. Rev. 1992, 92, 935.

13. a) Kunz, H.; Rück, K.; Angew. Chem. Int. Ed. Engl. 1993, 32, 336; b) Kunz, H.; Pure \& Appl. Chem. 1995, 67, 1627.

14. a) Ho, T.-L.; Enantioselective Synthesis: Natural Products From Chiral Terpenes; Jonh Wiley \& Sons, Inc.; New York, 1992; b) Oppolzer, W.; Tetrahedron 1987, 43, 1969.
15. a) Coppola, G. M.; Schuster, H.; Asymmetric Synthesis: Construction of Chiral Molecules Using Amino Acids; John Wiley \& Sons 1987; b) Hoffmann, R. W.; Angew. Chem. Int. Ed. Engl. 1987, 26, 489.

16. Fraser-Reid, B.; Mootoo, D. R.; Konradson, P.; Udodong, U. E.; Andrews, C. W.; Ratcliffe, A. J.; Wu, Z.; Yu, K. L.; Pure \& Appl. Chem. 1989, 61, 1243.

17. Pinheiro, S.; Farias, F. M. C.; Lima, M. B.; Alves, M. H.; Costa, P. R. R.; Resumos da $17^{a}$ Reunião Anual da Sociedade Brasileira de Química 1994.

18. Cubero, I.; Carbohydr. Res. 1994, 261, 231.

19. Araújo Filho, H. C.; Lima Filho, U. F.; Pinheiro,S.; Vasconcellos, M. L. A. A.; Costa, P. R. R.; Tetrahedron:Asymm. 1994, 5,1219.

20. a) Pinheiro, S.; Ferreira, V. F.; Araujo Filho, H. C.; Costa, P. R. R.; J. Braz. Chem. Soc. 1996, 7, 67; b) Pinheiro, S.; Ferreira, V. F.; Filho, H. C. A.; Costa, P. R. R.; Alencar, K. G.; Ferreira, C. M.; J. Carbohydr. Chem. 1996, 15, 691 .

21. Ireland, R. E.; Mueller, R. H.; Willard, A. K.; J. Am. Chem. Soc. 1976, 98, 2868.

22. a) Maddaluno, J. F.; Gresh, N.; Giessner-Prettre, C.; J. Org. Chem. 1994, 59, 793; b) Jones, G. B.; Chapman, B. J.; Synthesis 1995, 475.

23. Ferreira, V. F.; Quím. Nova 1995, 18, 267

24. Whitesell, J. K.; Felman, S. W.; J. Org. Chem. 1977, $42,1663$.

25. Oppolzer, W.; Dupuis, D.; Tetrahedron Lett. 1985, $26,5437$.

26. Oppolzer, W.; Dudfield, P.; Stevenson, T.; Godel, T.; Helv. Chim. Acta 1985, 68, 212.

27. Oppolzer,W.; Dudfield, D.; Helv. Chim. Acta 1985, 68, 216.

28. Oppolzer, W.; Dudfield, D.; Tetrahedron Lett. 1985, $26,5037$.

29. Oppolzer, W.; Pedrosa, R.; Moretti, R.; Tetrahedron Lett. 1986, 27,831.

30. Silva, C. V.; Pinheiro,S.; Costa, P. R. R.; Resumos do $6^{\text {th }}$ Brazilian Meeting on Organic Synthesis 1994.

31. Midland, M. M.; Chem. Rev. 1989, 89, 1553.

32. Brown, H. C.; Ramachandran, P. V.; Acc. Chem. Res. 1992, 25, 16 .

33. Cox, P. J.; Simpkins, N. S.; Tetrahedron:Asymm. 1991, $2,1$.

34. Simpkins, N.S.; Quím. Nova 1994, 17, 295.

35. a) Noyori, R.; Kitamura, M.; Angew. Chem. Int. Ed. Engl. 1991, 30, 49; b) Noyori, R.; Asymmetric Catalysis in Organic Synthesis; John Wiley \& Sons, Inc., N.Y. 1994; c) Weber, B.; Seebach, D.; Angew. Chem. Int. Ed. Engl. 1992, 31, 84

36. Santanielle, E.; Ferraboschi, P.; Grisenti, P.; Manzocchi, A.; Chem. Rev 1992, 92, 1071.

37. Pereira, R. S.; Quím. Nova 1995, 18, 295.

38. Azerard, R.; Bull. Soc. Chim. Fr. 1995, 132, 17.

39. Wong, C. H.; Whitesides, G.M.; Enzymes in Synthetic Organic Chemistry; Elsevier, Oxford 1994.

40. Seebach, D.; Behrendt, L.; Felix, D.; Angew. Chem. Int. Ed. Engl. 1991, 30, 1008.

41. Sih, C. J.; Chen, C. S.; Angew. Chem. Int. Ed. Engl. 1984, 23,570

42. Lok, K. P.; Jakovac, I. J.; Jones, J. B.; J. Am. Chem. Soc. 1985, 107, 2521.

43. Boland, W.; Frössl, C.; Lorenz, M.; Synthesis 1991, 1049.

44. Zhu, L. -M.; Tedford, M. C.; Tetrahedron 1990, 46, 6587.

45. a) Kilényi, S. N.; Aitken, R. A.; Asymmetric Synthesis; Aitken; R. A. and Kilényi, S. N.; Editors, Blackie Academic \& Professional, London 1992, cap. 6. b) Eliel, E. L.; Wilen, S. H.; Mander, L. N.; Stereochemistry of Organic Compounds; Wiley-Interscience, N.Y. 1994, 835.

46. Masamune, S.; Choy, W.; Petersen, J. S.; Sita, L. R.; Angew. Chem. Int. Ed. Engl. 1985, 24, 1.

47. Birkett, D. J.; Clin. Exp. Pharmacol. Physiol. 1989, 16, 479.

48. Fabro, S.; Smith, R. L.; Willian, R. T.; Nature 1967, 215, 296. 
49. Kumkumian, C. S.; Drug Inf. J. 1990, 24, 125.

50. DeCamp, W. H.; Chirality 1989, 1, 2.

51. a) Simonyi, M.; Gal, J.; Testa, B.; Problems and Wonder of Chiral Molecules; Simonyi, M. (ed.), Akademiai, Kiado, Budapest 1990, 127; b) Batra, S.; Seth, M.; Bhaduri, A. P.; Prog. Drug Res. 1993, 192; c) Testa, B.; Trager, W. F.; Chirality 1990, 2, 129.
52. Birkett, D. J.; Clin. Exp. Pharmacol. Physiol. 1989, 16, 479; USA Federal Register 57,17950, 1992.

53. Testa, B.; Mayer, J. M.; Progress Drug Res. 1988, 32, 249.

54. Garegg, P. J.; Acc. Chem. Res. 1992, 25, 575.

55. Cintas, P.; Tetrahedron 1991, 47, 6079.

56. Garegg, P. J.; Pure \& Appl. Chem. 1984, 56, 845.

57. Lichtenthaler, F. W.; Zuckerind 1990, 115, 762. 